\title{
DESENVOLVIMENTO DE NOVO AGENTE DESSILICIANTE DO GUSA ALTERNATIVO À CAREPA METÁLICA*
}

\author{
Otávio Augusto da Cunha Teixeira ${ }^{1}$ \\ Edilson Simões Cavalieri² \\ José Eustáquio Pinto ${ }^{3}$ \\ Wanderny Mendes Ribeiro ${ }^{4}$ \\ Welington Madureira Silva ${ }^{5}$ \\ Célio Adriano da Silva ${ }^{6}$
}

\section{Resumo}

Na Aperam South America, a geração interna de carepa metálica utilizada no PTG (Pré-tratamento de Gusa) como agente dessiliciante do gusa é insuficiente para suprir toda a demanda, sendo necessária a aquisição regular do insumo junto a outras siderúrgicas. Com o reaproveitamento interno da carepa pelas siderúrgicas, a compra do material no mercado ficou muito dificultada. Visando complementar a insuficiência do suprimento de carepa, foram estudadas e testadas duas alternativas de agente dessiliciante, tendo como fonte dois resíduos gerados no beneficiamento da carga metálica da Redução, a saber: Finos do Minério Serra Azul (100\%) e Finos de Pelota (80\%) misturados aos Finos de Minério Serra Azul (20\%). Após os testes, a segunda alternativa se mostrou mais viável técnica e economicamente. A taxa de dessiliciação do novo agente se apresentou, inclusive, melhor que a da própria carepa. A geração mensal do novo insumo (700 t), complementada com a da carepa interna, conseguem suprir integralmente a demanda de agente DeSi para o PTG.

Palavras-chave: Dessiliciante; Carepa; Dessiliciação; Desfosforação; Finos de pelota; Finos de minério; PTG.

\section{DEVELOPMENT OF NEW AGENT TO REDUCE THE SILICON CONTENT OF HOT METAL}

\section{Abstract}

At Aperam South America, the internal generation of metallic scale which is used as agent to Silicon reduction in Hot Metal Treatment (PTG) isn't sufficient to meet all the demand, requiring the regular purchasing from other steelmakers. With the internal reuse of scale by the steel plants, the purchase of this material has become very difficult, compromising the supply of whole Aperam's demand. In order to complement the lack of scale supply, were studied and tested two alternative of DeSi agents whose source are coming from the metallic charge of blast furnaces, i.e.: Serra Azul iron ore fines ( $100 \%)$ and fines of pellets $(80 \%)$ mixed with Serra Azul iron ore fines (20\%). After the tests, the second alternative was shown technically and economically more feasible. The rate of Si reduction of the new agent that was developed proved be better even than the normal scale generated at Hot Rolling Mill (HRM). The monthly generation of new material developed (700 t), complemented with the scale generated at HRM, can fully supply the DeSi agent demand for PTG.

Keywords: Hot metal Si reduction; Scale; Dephosforization; Iron ore \& pellets fines.

\footnotetext{
Eng ${ }^{\circ}$ Metalurgista, Analista Consultor, Aperam South America, Timóteo, Minas Gerais, Brasil.

Contador, Analista Técnico PTG, Aperam South America, Timóteo, Minas Gerais, Brasil.

Administrador, Assistente Gestão Aciaria, Aperam South America, Timóteo, Minas Gerais, Brasil.

Administrador, Analista de Suprimentos, Aperam South America, Timóteo, Minas Gerais, Brasil.

Contador, Analista Técnico Matérias Primas, Aperam South America, Timóteo, Minas Gerais, Brasil.

6 Técnico Metalúrgico, Supervisor Mat. Primas, Aperam South America, Timóteo, Minas Gerais, Brasil.
} 


\section{1 - INTRODUÇÃO}

O Pré-tratamento de Gusa (PTG) da usina da Aperam, em Timóteo-MG, tem como função principal a realização de tratamentos no gusa que é utilizado na composição da carga dos convertedores AOD-L e/ou MRP-L onde é feito o refino primário dos aços inoxidáveis, elétricos e carbono. Basicamente, o PTG (vide Figura 1) é composto por uma estação de dessiliciação (DeSi), que fica localizada onde ocorre a virada do gusa dos carros torpedos, e por duas estações equipadas para realizarem os processos de desfosforação (DeP) e/ou dessulfuração (DeS), ambas providas de um carro panela e de um carro pote, assim como de um raspador para remoção da escória gerada em diferentes etapas do processo.

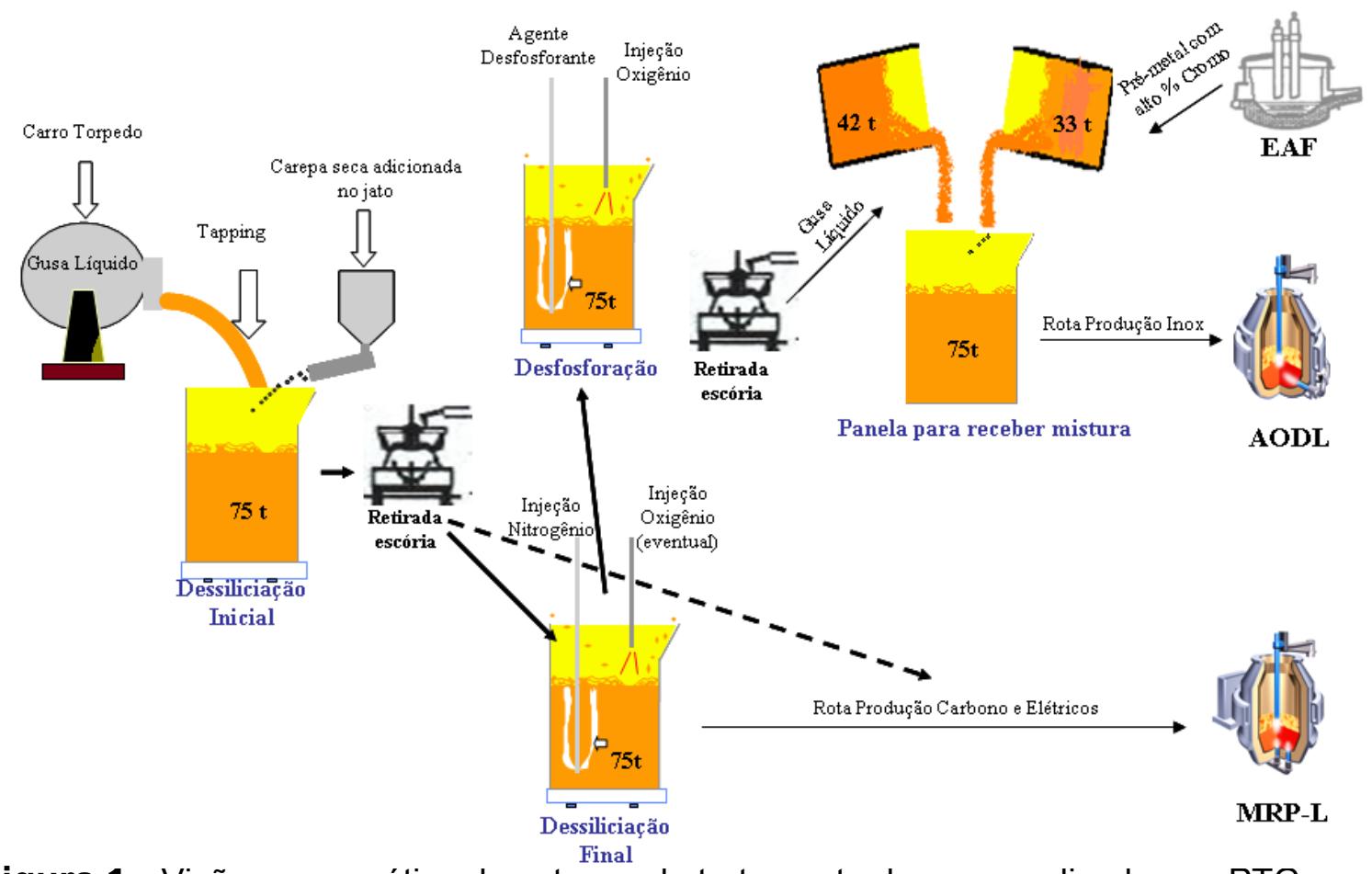

Figura 1 - Visão esquemática das etapas de tratamento de gusa realizadas no PTG

Para a produção dos aços inoxidáveis utilizando-se o gusa como parte da carga dos convertedores é fundamental que o mesmo seja previamente desfosforado, visto que tal reação é extremamente dificultada na presença de cromo (elemento presente em todos os aços inoxidáveis), devido à sua maior afinidade com o oxigênio que o fósforo [1]. Dessa forma, a DeP tem que ocorrer antes da mistura do gusa tratado com o pré-metal rico em cromo oriundo dos FEAs e antes do carregamento dos convertedores, onde são complementadas as adições de Ferro Cromo.

O processo DeP tem que ser feito em ambiente oxidante, ou seja, deve ser adicionado um agente desfosforante com afinidade ao oxigênio menor que o fósforo, ou até mesmo injetar o oxigênio gasoso puro [2]. Para haver uma maior estabilidade do óxido de fósforo gerado deve-se adicionar o $\mathrm{CaO}$ para formar um fosfato de cálcio que será facilmente absorvido pela escória gerada no processo. A reação química principal envolvida no processo é:

$2[\mathrm{P}]+5 / 2 \mathrm{O}_{2}+4(\mathrm{CaO}) \Rightarrow\left(\mathrm{P}_{2} \mathrm{O}_{5} .4 \mathrm{CaO}\right)$

ou quando o oxigênio é proveniente do minério de ferro:

$6[\mathrm{P}]+5\left(\mathrm{Fe}_{2} \mathrm{O}_{3}\right)+12(\mathrm{CaO}) \Rightarrow 5[\mathrm{Fe}]+3\left(\mathrm{P}_{2} \mathrm{O}_{5} .4 \mathrm{CaO}\right)$ 
Pelas reações acima, fica claro que a DeP é mais eficiente quando o potencial de oxigênio do ambiente é mais elevado e quando a basicidade da escória é mais alta (maior concentração de $\mathrm{CaO}$ ). Estas condições são incompatíveis com altos teores de silício do gusa a ser tratado, em função da maior afinidade deste com o oxigênio quando comparado ao fósforo, além da inconveniente formação de $\mathrm{SiO}_{2}$ e consequente redução da basicidade da escória. Por estes motivos, é imprescindível que a DeP seja precedida de um bom processo de DeSi (dessiliciação) do gusa. O teor de silício do gusa objetivado após a dessiliciação e antes que se inicie a desfosforação deve estar abaixo de 0,20\%.

$\mathrm{Na}$ produção de aços elétricos e carbono, cujo refino primário se dá no MRP-L, a presença de teores de silício no gusa acima de 0,6 \% é indesejável, tanto pela maior necessidade de adição de fundentes no convertedor como pelo aumento das reações e projeções e, por consequência, menor rendimento metálico do processo. Nestes casos, também é imprescindível que se faça uma DeSi prévia do gusa.

A reação química principal envolvida na dessiliciação é expressa pela equação:

\section{$[\mathrm{Si}]+2(\mathrm{FeO}) \Rightarrow 2[\mathrm{Fe}]+\left(\mathrm{SiO}_{2}\right)$}

A temperatura envolvida no processo de dessiliciação varia de 1250 a $1350^{\circ} \mathrm{C}$. A DeSi, normalmente, tem sua etapa inicial realizada durante a transferência do gusa do carro torpedo para a panela, adicionando-se, neste período, um agente dessiliciante, aproveitando-se a agitação provocada pelo jato de metal para melhorar a cinética da reação. Como agentes dessiliciantes são normalmente empregados resíduos gerados na própria usina que contêm óxido de ferro e que passam por algum tipo de beneficiamento posterior (secagem, por exemplo). Entre estes resíduos, o principal deles é a carepa oriunda do processo de laminação a quente (LTQ). O agente dessiliciante deve ser fino, preferencialmente menor que $10 \mathrm{~mm}$ para que haja maior interface de reação, melhorando o rendimento do processo.

Até 2002, quando a produção de não planos foi descontinuada, a Aperam era autossuficiente no suprimento de carepa metálica para uso no PTG. A partir de então, apenas a geração interna da LTQ não tem sido suficiente para suprir toda a demanda, exigindo-se a aquisição regular do insumo junto a outras siderúrgicas. Entretanto, nos últimos anos, em função da adoção de políticas de redução de custos aliadas à reutilização dos resíduos nos seus próprios processos, as siderúrgicas também têm feito o reaproveitamento da carepa metálica gerada internamente. Esta condição tornou a aquisição do insumo muito difícil, tanto pela baixa oferta como pelos custos elevados quando há alguma disponibilidade para venda, comprometendo-se, seriamente, o abastecimento da Aciaria da Aperam.

Para complementar a insuficiência do suprimento quando se utiliza apenas a carepa de geração interna, foram estudadas e testadas, entre novembro/12 e agosto/13, duas alternativas de agente dessiliciante. Este trabalho mostra os resultados obtidos nos testes realizados, a análise técnica das alternativas e as definições adotadas para continuar garantindo o pleno suprimento, tanto em volume como em efetividade de dessiliciação, de um insumo crítico para o processo produtivo da empresa.

\section{2 - DESENVOLVIMENTO}

\section{1 - Histórico sobre as fontes de agentes dessiliciantes utilizados no PTG}

Os materiais utilizados como agente dessiliciante contém, via de regra, a presença de óxido de ferro em sua constituição. São normalmente empregados materiais/resíduos gerados na própria usina como, por exemplo, as carepas de 
laminação a quente e, eventualmente, também a carepa de lingotamento contínuo e, em menor escala, pós de sistemas de desempoeiramento. Os finos de sínter gerados no processo de sinterização e, principalmente, os finos de minério de ferro, obtidos após os processos de lavagem e peneiramento, também têm muito boa eficiência como dessiliciantes. Duas condições muito importantes têm que ser obedecidas para se ter um bom agente dessiliciante, a saber:

- a granulometria que deve ficar compreendida entre 0,5 e $10 \mathrm{~mm}$, para propiciar, primeiramente, uma maior interface de reação, melhorando o rendimento do processo e, adicionalmente, evitar que os particulados menores que $0,50 \mathrm{~mm}$ sejam sugados pelo sistema de desempoeiramento

- a umidade presente no material tem que estar abaixo de 1,0\% para se evitar qualquer risco de reação descontrolada e projeção de metal líquido .

$\mathrm{Na}$ Aperam, a carepa gerada na laminação de barras grossas supria toda a necessidade de agente dessiliciante no início de operação do PTG. Esta situação perdurou até meados de 2002, quando foi descontinuada a linha de não planos.

Paralelamente ao uso dos finos de sínter que foram usados por um curto período, foi desenvolvida a utilização da carepa gerada na laminação de tiras a quente (LTQ). Após a coleta através de dragagem do hidrociclone, a carepa, ainda úmida, é enviada para secagem nas instalações de um prestador de serviço externo. A quantidade de carepa da LTQ reaproveitada para uso no processo de dessiliciação do gusa no PTG tem variado, recentemente, entre 500 e aprox. 600 t mensais já após o processo de secagem. A umidade presente na carepa, antes da secagem, situa-se entre 5 e $7 \%$.

Ressalta-se, entretanto, que demanda total típica de agente DeSi no PTG é da ordem de $1.000 \mathrm{t} /$ mês que, eventualmente, pode chegar até a 1.200 toneladas mensais. Dessa forma, atualmente, a reciclagem interna da carepa da LTQ colabora com o suprimento de 50 a $60 \%$ da necessidade da Aciaria.

O suprimento do restante da demanda de agente DeSi vinha sendo feito, desde o final de 2002, através da aquisição regular do insumo de outras siderúrgicas. O fornecimento externo foi iniciado com a compra de carepas geradas em duas plantas siderúrgicas de produtos longos o que, entretanto, não se consolidou em função de dificuldades de logística e do elevado custo de frete. Como alternativa, em meados de 2003, viabilizou-se o fornecimento regular de carepa metálica junto à Usiminas que, além da proximidade de Timóteo, ofertou, desde o início da parceria, material de boa qualidade, atendendo aos requisitos especificados de granulometria, conteúdo metálico e isenção de contaminantes indesejáveis como óleos e graxas.

Entretanto, a Usiminas, que desde 2003 fornecia toda a necessidade suplementar de carepa metálica, se posicionou, no final de 2012, pela descontinuidade das vendas do material, em função da destinação mais atrativa que ela encontrou internamente, através da reutilização do insumo no seu próprio processo produtivo. Após tal posicionamento da Usiminas, a área de Suprimentos da Aperam realizou contatos com outras siderúrgicas que declinaram em relação a um eventual fornecimento, em condições economicamente viáveis para ambas as partes, devido a tais empresas também passarem a reciclar a sua própria carepa.

Diante da grande dificuldade colocada para aquisição de carepa no mercado, em novembro de 2012, foi formada uma força-tarefa multidisciplinar, que envolveu as áreas da Aciaria, Suprimentos e Redução, para estudar e desenvolver alternativas para complementar o abastecimento de agente dessiliciante ao nível da demanda total do insumo para atender à necessidade de dessiliciação do gusa no PTG. 


\section{2 - Estudo e desenvolvimento de alternativas para o pleno atendimento à demanda de agente DeSi}

Dentro do objetivo de se buscar alternativas para garantir o pleno abastecimento de agente dessiliciante para o PTG, numa primeira avaliação feita pela equipe da forçatarefa a partir da similaridade entre a composição química do sínter (cujos finos foram usados como agente DeSi no início dos anos 2000) e a do minério de ferro, vislumbrou-se a possibilidade de se utilizar os finos de minério gerados no beneficiamento (lavagem e peneiramento) na área de Redução para promover a dessiliciação do gusa líquido na Aciaria.

\subsection{1 - Finos do minério fornecido pela Vale}

Como primeira ação, no início de novembro de 2012, foi feito um teste com cerca de $9 \mathrm{t}$ de finos do minério fornecido pela Vale, que foram previamente secos e utilizados na dessiliciação de 6 panelas de gusa. Considerando-se os objetivos iniciais propostos, os resultados preliminares foram satisfatórios, tendo sido observada tanto uma boa diluição dos finos de minério no gusa líquido durante a adição (na virada do torpedo) como um nível de emissão de particulados semelhante ao que ocorre com o uso da carepa. Estes resultados iniciais motivaram ainda mais a equipe no sentido de dar continuidade no desenvolvimento de um novo agente dessiliciante a partir do reaproveitamento de finos de minério gerados internamente. Conforme Tabela 1, apesar de possuir um teor de ferro total bem razoável $(58,8 \%)$, os finos do minério da Vale têm uma fração granulométrica abaixo de $0,50 \mathrm{~mm}$ bem elevada (aprox. $55 \%$ ), o que é uma condição desfavorável para se ter um bom rendimento no processo de dessiliciação.

\subsection{2 - Finos do minério fornecido pela Mineração Serra Azul}

Considerando-se que os finos gerados no beneficiamento do minério fornecido pela Vale são comercializados a um preço relativamente atrativo, decidiu-se pelo prosseguimento das experiências, concentrando-se as ações, entretanto, na viabilização do reaproveitamento dos finos oriundos do beneficiamento do minério Serra Azul, cuja remoção da usina vinha sendo feita mediante o pagamento de valor simbólico. Dentro desta premissa, foram secas cerca de $20 \mathrm{t}$ dos finos do minério Serra Azul que foram testadas entre os dias 21 e 22/11/12, em 12 corridas do PTG. Apesar do pequeno número de corridas experimentais, pôde-se observar uma boa diluição do material no gusa líquido assim como uma razoável taxa de dessiliciação, principalmente para as corridas em que a temperatura do gusa se encontrava em condição normal (temperatura no canal dos AF's maior que $1400{ }^{\circ} \mathrm{C}$ ).

A partir dos resultados dos testes iniciais e devido à baixa disponibilidade de carepa em estoque no final de 2012, decidiu-se dar sequência na utilização dos finos do minério Serra Azul, sendo encaminhada a secagem de mais $200 \mathrm{t}$ para se comprovar sua viabilidade técnica através do uso em maior escala. Este segundo teste confirmou a possibilidade do uso dos finos do minério Serra Azul como agente DeSi, complementando a demanda do PTG que não poderia ser suprida apenas com a carepa gerada internamente na LTQ. Os finos do minério Serra Azul, após a secagem, foram usados de forma rotineira e em separado da carepa de dezembro/12 até o final de agosto/13.

Neste período, entretanto, da forma como vinha sendo beneficiado, sendo submetido apenas à secagem, sem se utilizar qualquer processo de concentração metálica, observava-se que os finos do minério Serra Azul, conforme Tabela 1, 
apresentavam um baixo teor de ferro total (cerca de 54\%) e um elevado teor de ganga com alta concentração de $\mathrm{SiO}_{2}$ (teores acima de 15\%), o que prejudicava bastante a sua eficiência como agente dessiliciante. Outra característica negativa de tal resíduo era a sua elevada quantidade de finos abaixo de $0,50 \mathrm{~mm}(>40 \%$ do total), o que facilitava bastante que tais particulados fossem sugados pelo sistema de desempoeiramento durante a adição do agente na virada do gusa líquido do torpedo para a panela, prejudicando sobremaneira o rendimento na sua aplicação.

\subsection{3 - Finos de pelota misturados aos finos do minério Serra Azul}

Devido às características limitantes dos finos do minério Serra Azul em relação à composição química e à granulometria, entre maio e junho/13, analisou-se a possibilidade de se reaproveitar os finos do minério da Vale, em função deles possuírem melhor qualidade, com um \% Fe total próximo de $60 \%$ e um $\% \mathrm{SiO}_{2}$ da ordem de 9,0\%. Entretanto, para se atender uma demanda de até $600 \mathrm{t} / \mathrm{mês}$ de finos secos na granulometria acima de $0,50 \mathrm{~mm}$, a partir dos finos do minério da Vale, estimou-se uma necessidade de se ter que processar um volume global de 1.500 t/mês de finos (base úmida), o que geraria uma quantidade de resíduos menor que $0,50 \mathrm{~mm}$ entre 700 e $800 \mathrm{t} / \mathrm{mês}$ (base úmida). Após o peneiramento, em testes de laboratório, os resíduos abaixo de $0,50 \mathrm{~mm}$ apresentaram 1,5\% de Ferro menor e $1,5 \%$ de $\mathrm{SiO}_{2}$ maior em relação aos valores típicos retornados à Vale até então. Tais características do subproduto, que seria gerado após o peneiramento, inviabilizaram a adoção dos finos do minério da Vale como alternativa, devido às eventuais dificuldades para a comercialização ou disposição do rejeito produzido.

Em agosto/13, foi sugerida pela equipe de Matérias Primas da Redução uma alternativa que se mostrou, desde o princípio, muito interessante, que foi 0 reaproveitamento dos finos de pelota misturados aos finos do minério Serra Azul (após lavagem), resíduos estes gerados e separados antes do abastecimento do Alto Forno 2. A geração diária destes finos gira em torno de 30 toneladas, o que significa cerca de 900 t mensais na base úmida ou aproximadamente $700 \mathrm{t}$ após a secagem. O teor médio de ferro contido neste resíduo fica acima de $58,0 \%$ e mais de $70 \%$ do material se enquadra na faixa granulométrica acima de $1,0 \mathrm{~mm}$, conforme mostra a Tabela 1. Desde o princípio de agosto/13 foi dada prioridade na secagem destes finos para confirmação de sua eficiência como agente dessiliciante. Com um agente mais rico em óxido de ferro e com uma granulometria mais adequada, previu-se uma melhora no processo de dessiliciação assim como um melhor rendimento do material devido à menor perda por sucção pelo desempoeiramento. Os resultados foram confirmados nos testes realizados ainda em agosto de 2013 e estão demonstrados no tópico a seguir que trata dos resultados do presente trabalho.

\section{3 - RESULTADOS E DISCUSSÃO}

\section{1 - Processo de Dessiliciação}

A dessiliciação (DeSi) tem sua etapa inicial realizada durante a transferência do gusa do carro torpedo para a panela, adicionando-se, neste período, um agente dessiliciante, aproveitando-se a agitação provocada pelo jato de metal para melhorar a cinética da reação (Figura 2). 


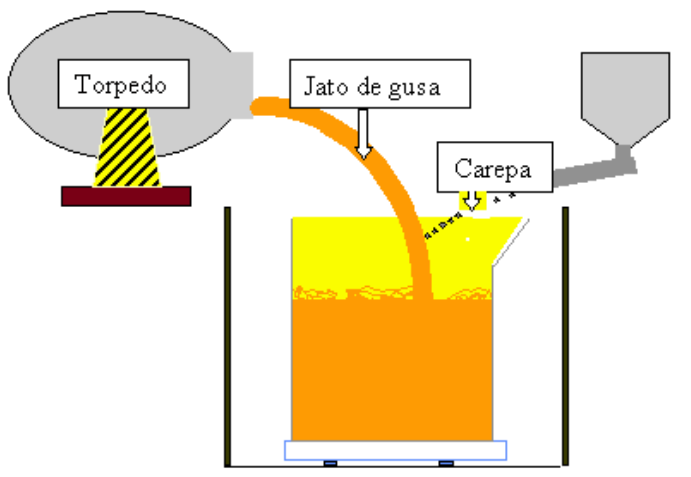

Figura 2 - Visão esquemática da dessiliciação do gusa na panela na virada do carro torpedo

A temperatura envolvida neste processo varia de 1250 a $1350^{\circ} \mathrm{C}$. A reação química principal envolvida no processo é: $[\mathrm{Si}]+2(\mathrm{FeO}) \Rightarrow 2[\mathrm{Fe}]+\left(\mathrm{SiO}_{2}\right)$

Posteriormente à DeSi inicial, a panela é transferida para uma das estações do PTG, onde é feita uma homogeneização através de injeção profunda de nitrogênio que pode ou não ser acompanhada por sopro de oxigênio pela lança de topo, caso a temperatura esteja baixa e/ou o teor de silício ainda não tenha atingido o percentual desejado. Terminada a homogeneização / aquecimento, é feita a remoção da escória formada antes de se passar para a DeP (no caso dos aços inoxidáveis) ou o envio da panela para carregamento do MRP-L (para os aços elétricos e carbono).

\section{2 - Caracterização físico-química dos agentes dessiliciantes testados no PTG}

A Tabela 1 mostra um resumo das principais características físico-químicas dos resíduos internos utilizados nos testes para desenvolvimento de um insumo adicional à carepa metálica, assim como as informações relativas à própria carepa para efeito de comparativo.

Tabela 1 - Características dos insumos testados como Agente DeSi no PTG

\begin{tabular}{|c|c|c|c|c|c|c|}
\hline \multirow{2}{*}{$\begin{array}{l}\text { INSUMO I } \\
\text { RESIDUO }\end{array}$} & \multicolumn{2}{|c|}{ DISTRIBUIÇÃO GRANULOMÉTRICA } & \multicolumn{4}{|c|}{ ANÁLISE QUIMMICA TÍPICA } \\
\hline & Fração $<0,50 \mathrm{~mm}$ & Fração $\geq 0,50 \mathrm{~mm}$ & $\begin{array}{r}\% \text { Fe Total } \\
\text { (sem Oxigênio) }\end{array}$ & $\% \mathrm{SiO}_{2}$ & $\% \mathrm{P}$ & $\begin{array}{c}\begin{array}{c}\% \mathrm{CaO}+\% \mathrm{MgO}+ \\
\% \mathrm{Al} 2 \mathrm{O} 3\end{array} \\
\end{array}$ \\
\hline CAREPA & $55,9 \%$ & $44,1 \%$ & $78,3 \%$ & \multicolumn{3}{|c|}{ Balanço: Oxigênio } \\
\hline $\begin{array}{l}\text { Finos Minério } \\
\text { VALE }\end{array}$ & $54,6 \%$ & $45,4 \%$ & $58,8 \%$ & $9,3 \%$ & $0,10 \%$ & $3,1 \%$ \\
\hline $\begin{array}{l}\text { Finos Minério } \\
\text { SERRA AZUL }\end{array}$ & $42,1 \%$ & $57,9 \%$ & $54,4 \%$ & $15,4 \%$ & $0,06 \%$ & $2,8 \%$ \\
\hline $\begin{array}{c}\text { Finos PELOTA }(80 \%) \\
+ \text { Finos SERRA AZUL (20\%) }\end{array}$ & $26,3 \%$ & $73,7 \%$ & $58,9 \%$ & $9,7 \%$ & $0,07 \%$ & $2,8 \%$ \\
\hline
\end{tabular}

\section{3 - Resultados dos testes com os resíduos alternativos à carepa}

A Tabela 2 consolida as informações e resultados obtidos ao longo de 2013, relativos aos testes e à utilização de rotina dos resíduos finos do minério Serra Azul e finos de pelota / minério Serra Azul. Para efeito de comparativo, as características da carepa também estão registradas. Como premissa básica, foram selecionadas apenas as corridas que tenham utilizado gusa líquido cuja temperatura no canal dos Altos Fornos estivesse entre 1410 e $1420^{\circ} \mathrm{C}$. A temperatura do gusa líquido é uma variável chave em relação ao consumo de agente dessiliciante. Temperaturas mais elevadas do gusa permitem maiores adições de agente dessiliciante por facilitarem a sua diluição, o que contribui para uma melhor efetividade do processo. 
Tabela 2 - Análise comparativa da eficiência de dessiliciação dos resíduos testados no PTG

\begin{tabular}{|l|c|c|c|}
\hline \multirow{2}{*}{ Parâmetros } & \multicolumn{2}{c|}{ Valores Médios por Agente / Resíduo Aplicado } \\
\cline { 2 - 4 } & Carepa & $\begin{array}{c}\text { Finos Minério } \\
\text { Serra Azul }\end{array}$ & $\begin{array}{c}\text { Finos Pelota + } \\
\text { Min. Serra Azul }\end{array}$ \\
\hline Temperatura no canal dos AF's ( $\left.{ }^{\circ} \mathrm{C}\right)$ & 1419 & 1413 & 1415 \\
\hline \%Si do gusa no canal dos AF's & 0,79 & 0,99 & 0,79 \\
\hline \%Si do gusa após adição de agente no PTG & 0,48 & 0,72 & 0,46 \\
\hline \% Redução no \% Si do gusa & $39,1 \%$ & $27,7 \%$ & $\mathbf{4 1 , 4 \%}$ \\
\hline Adição média por panela no PTG (kg) & 1.927 & 2.124 & 1.644 \\
\hline Kg agente para reduzir $\mathbf{0 , 0 1 \% ~ d e ~ S i ~}$ & 62,40 & 77,29 & $\mathbf{5 0 , 4 6}$ \\
\hline
\end{tabular}

\subsection{1 - Análise dos resultados e definição do agente DeSi alternativo à carepa}

Conforme mostra a Tabela 2, o resíduo de finos de pelota misturado com os finos do minério Serra Azul se apresentou como um excelente insumo para promover a dessiliciação do gusa, com eficiência superior até mesmo em relação à da própria carepa. O nível de redução do \% Si foi de cerca de $41 \%$ contra quase $28 \%$ dos finos de minério Serra Azul utilizados de forma isolada. Pela sua maior granulometria, que dificulta a possibilidade do arraste pelo sistema de desempoeiramento, a quantidade aplicada de finos de pelota/minério Serra Azul para dessiliciar $0,01 \%$ de Si foi $35 \%$ menor que a dos finos de Serra Azul, atingindo um consumo específico de 50,46 contra $77,29 \mathrm{~kg} / \mathrm{t}$, respectivamente. Outros dois fatores que também contribuíram bastante para o bom desempenho deste novo agente em relação aos finos de minério Serra Azul (quando usados isoladamente) foram: o teor de Fe total acima de $58,0 \%$ e o $\% \mathrm{SiO}_{2}$ menor que $10 \%$. Por estes motivos, aliados à geração de volume mais do que suficiente (cerca de $700 \mathrm{t}$ mensais) para suprir a parte da demanda não acobertada apenas com a carepa oriunda da LTQ, ficou caracterizada a viabilidade de se aproveitar os finos de pelota / finos de minério Serra Azul como agente DeSi.

\subsection{2 - Evolução do consumo de agentes dessiliciantes usados no PTG}

Desde meados de 2012, os tipos e quantidades de insumos utilizados como agentes dessiliciantes passaram por mudanças consideráveis, conforme ilustra a Figura 3.

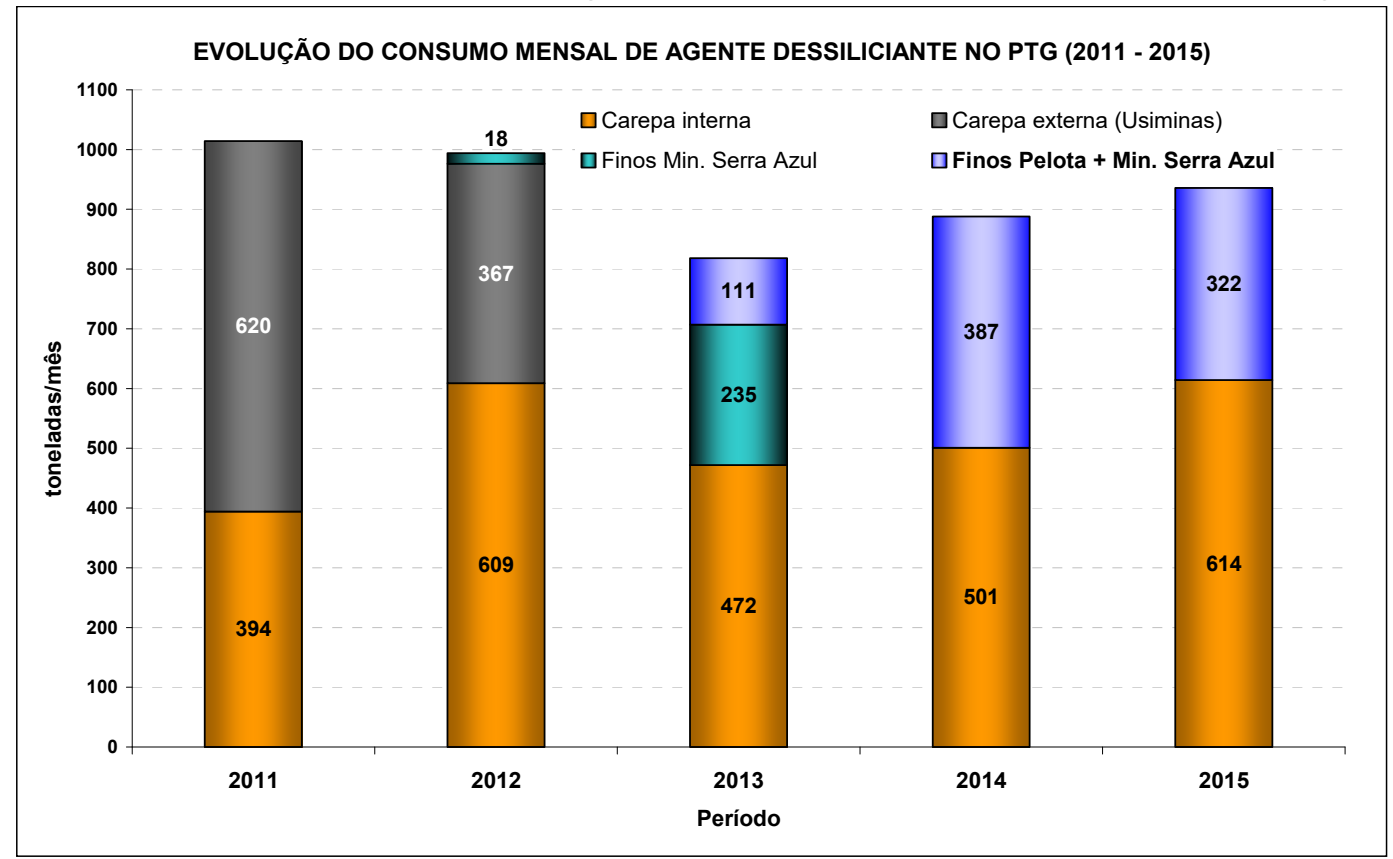

Figura 3 - Consumo médio mensal dos agentes dessiliciantes usados no PTG (2011/ 2015) 
Até 2011 , cerca de $60 \%$ do suprimento de agente DeSi era proveniente da aquisição de fonte externa de carepa (Usiminas), complementada pela carepa interna da LTQ. Já no segundo semestre de 2012, com a descontinuação do fornecimento pela Usiminas e inexistência de fonte alternativa já desenvolvida, foi necessário utilizar todo o estoque remanescente de carepa de geração própria, cujo consumo médio mensal, ao longo de todo o ano de 2012, representou $60 \%$ do total de agente DeSi consumido. Em novembro/12, já numa situação crítica em termos de abastecimento de agente DeSi, iniciou-se a utilização dos finos de minério Serra Azul. Foram consumidas cerca de 210 toneladas no último bimestre de 2012 ou $18 \mathrm{t}$ de média mensal no ano em questão. Devido às características não adequadas dos finos do minério Serra Azul, desenvolveu-se, com sucesso, a partir de agosto/13, a aplicação do novo agente dessiliciante que teve como base o resíduo composto por $80 \%$ de finos de pelota e $20 \%$ de finos de minério Serra Azul. Pode-se observar na Figura 3 que o consumo deste insumo alternativo já foi bem significativo em 2013, representando cerca de $14 \%$ do consumo médio mensal (111 t mensais), sendo que o seu uso só se iniciou, efetivamente, a partir de setembro/13. Em 2013, a principal causa do declínio no consumo de agente DeSi se deveu à baixa temperatura média do gusa quando comparada com a dos outros anos, conforme pode ser observado na Figura 4. Tal condição limitou, por questões de balanço térmico, uma maior utilização de agente DeSi. Nos anos de 2014 e 2015, a aplicação dos finos de pelota e de minério Serra Azul representou 43\% e 34\% do consumo médio mensal, respectivamente. A menor taxa de utilização em 2015 é explicada pela maior geração interna de carepa na LTQ, que é sempre a primeira opção de consumo em relação aos demais insumos usados na dessiliciação do gusa.

\subsection{3 - Evolução do consumo específico médio global de agentes dessiliciantes usados no PTG}

O consumo de agente DeSi está diretamente associado a dois fatores: a temperatura do gusa e ao \% de silício do gusa a ser dessiliciado. A curva da Figura 4 mostra a evolução do consumo específico médio global de agente DeSi no PTG de 2011 a 2015.

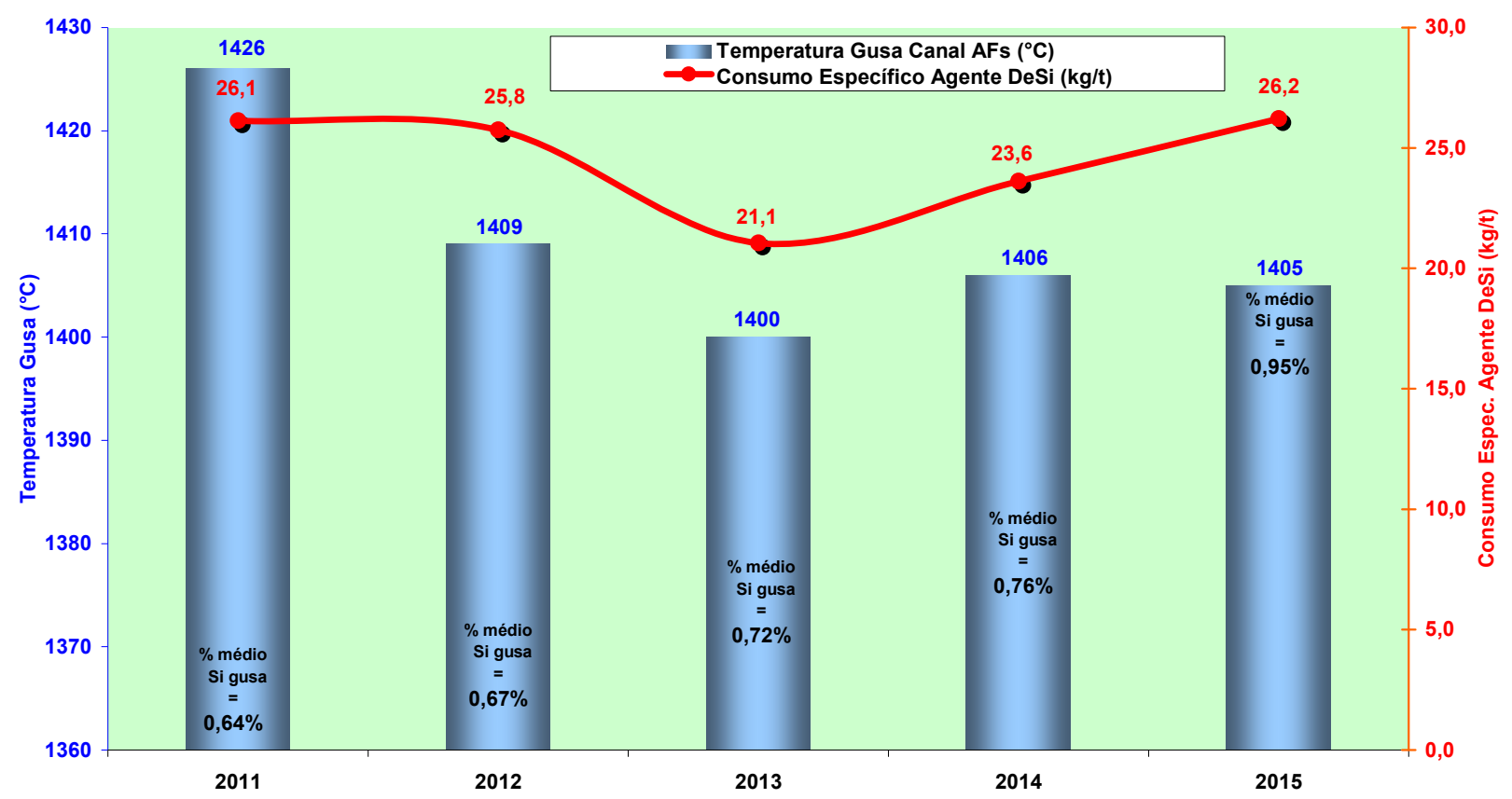

Figura 4 - Consumo específico de agente DeSi x Temperatura e \% Silício médios do gusa 
Observando a Figura 4, fica nítida uma redução no consumo de agente DeSi no ano de 2013 (aprox. $21 \mathrm{~kg} / \mathrm{t}$ ) comparado ao praticado no período de 2011/2012, que estava situado num patamar próximo de $26 \mathrm{~kg} / \mathrm{t}$. A explicação está vinculada à forte queda da temperatura média do gusa que saiu dos $1426^{\circ} \mathrm{C}$ em 2011 (condição muito influenciada pela operação do AF2 com coque até junho/11) para um patamar de $1400^{\circ} \mathrm{C}$ em 2013 (AF2 operando com carvão vegetal). Apesar do incremento do teor do silício da gusa (de 0,64\% em 2011 para 0,72\% em 2013), a drástica redução da temperatura do gusa preponderou para que houvesse uma queda significativa do consumo de agente DeSi. A adição do insumo fica limitada para situações de temperaturas mais baixas da gusa, em função da dificuldade de diluição e homogeneização do material no metal líquido. A partir de 2014, quando se consolidou a utilização dos finos de pelota e de minério Serra Azul, observa-se um crescimento no consumo específico médio de agente DeSi comparado ao de 2013, passando para 23,6 kg/t em 2014 e atingindo 26,2 kg/t em 2015. Além de um incremento de 5 a $6^{\circ} \mathrm{C}$ na temperatura do gusa em relação ao praticado em 2013, a razão principal deste aumento se deveu à forte elevação do teor de silício do gusa que atingiu 0,95\% em 2015, em função de instabilidade operacional do AF2. Em 2015, mesmo com níveis de temperatura mais baixos que os de 2011 , intensificouse o consumo de agente DeSi para fazer frente ao teor muito alto do silício do gusa. Pode-se concluir que a introdução do resíduo gerado do peneiramento de pelota e finos do minério Serra Azul tem cumprido bem o seu papel de agente DeSi eficiente, não tendo alterado o perfil de consumo global dos insumos usados na dessiliciação.

\section{4 - CONCLUSÕES}

Foram estudadas e testadas duas alternativas para complementação do abastecimento de agente dessiliciante demandado pelo PTG, a saber: finos do minério Serra Azul (100\%) e finos de pelota (80\%) misturados aos finos de minério Serra Azul (20\%). Os resultados e definições adotadas foram os seguintes:

a) O resíduo constituído pelos finos de pelota misturados com os finos do minério Serra Azul se apresentou como um ótimo insumo para a dessiliciação do gusa. A redução do \% silício do gusa foi de aprox. $41 \%$ contra cerca de $28 \%$ dos finos de minério Serra Azul utilizados de forma isolada.

b) Pela sua maior granulometria, além de uma boa concentração de Fe total (maior que 58\%) e um teor de $\mathrm{SiO}_{2}$ razoável (menor que 10\%), a quantidade aplicada de finos de pelota/minério Serra Azul para dessiliciar $0,01 \%$ de Si foi $35 \%$ menor que a dos finos de Serra Azul (50,46 contra 77,29 kg/t).

c) Como os resultados técnicos dos testes foram satisfatórios e o volume gerado de finos de pelota misturados aos finos do minério Serra Azul (aprox. 700 t/mês) é suficiente para suprir a parte da demanda não acobertada apenas com a carepa da LTQ ficou, assim, confirmada a viabilidade de se aproveitar tal resíduo como um novo agente dessiliciante no PTG.

d) Em 2014 e até julho de 2015, a aplicação deste novo agente representou, respectivamente, $43 \%$ e $34 \%$ do consumo global de agente DeSi no PTG.

\section{REFERÊNCIAS}

1) LIMA, F. A. ; PINTO, J.E. et alii. Estado da Arte do Processo de Desfosforação de Gusa na Acesita. Contribuição técnica para o $55^{\circ}$ Congresso Anual da ABM, 24 a 28 de Julho de 2000, Rio de Janeiro, 12p.p.

2) Apostila da Escola de Qualificação de Aciaristas da ArcelorMittal Inox Brasil. Módulo: PRÉ-TRATAMENTO DE GUSA. 2008. 33 p.p. 